\title{
The general problem of increased somatic comorbidity in bipolar patients
}

\author{
Julio Bobes \\ From $1^{\text {st }}$ International Congress on Neurobiology and Clinical Psychopharmacology and European Psychia- \\ tric Association Conference on Treatment Guidance \\ Thessaloniki, Greece. 19-22 November 2009
}

There is an increasing recognition that bipolar disorder is associated with elevated mortality and morbidity rates. Although there are still some doubts whether schizophrenia impairs physical health more than other disorders, recent papers $[1,2]$ have demonstrated that bipolar disorder impairs metabolic and cardiovascular systems as much as schizophrenia.

Reported prevalence of metabolic syndrome (MetS) in patients with bipolar disorder varies from $18 \%$ to $32 \%$ in the European Union (EU) and 40\% to $49 \%$ in the United States of America (USA). These rates are substantially higher than that reported for the general population (15\% EU, 27\% USA) [3], and very similar to that reported for patients with schizophrenia (19.4\% to $44.7 \%$ ). Much less attention has been paid to cardiovascular risks in these patients. Two recently published studies $[1,4]$ demonstrated higher cardiovascular risk level than the general population. Furthermore, the Spanish study [4] demonstrated that Spanish patients with bipolar disorder were exposed to the same cardiovascular risk level as Spanish patients with schizophrenia.

Unpublished data from our comparative study on physical health in patients with bipolar disorder versus patients with schizophrenia shown that bipolar disorder impairs physical health even more than schizophrenia. There were not statistical significant differences according to diagnosis neither in MetS rates (21.4\% of patients with bipolar disorder versus $28.7 \%$ of patients with schizophrenia, $\mathrm{p}$ 0.315), nor in the mean body mass index (bipolar $=30.3$ versus schizophrenia $=30 \mathrm{~kg} / \mathrm{m} 2$, p 0.723), or in the BMI categories (obesity: bipolar = $43.4 \%$ versus schizophrenia $=43 \%$, p 0.964). However, patients with bipolar disorder reported greater proportion of hypertension than patients with schizophrenia (19.6\%

\footnotetext{
University of Oviedo, (Asturias) and Psychiatric Services for the Oviedo Area,
} Spain versus $6.2 \%, \mathrm{p}$ 0.008) and met criterion 4 -elevated blood pressure- for MetS in a greater proportion too $(35.7 \%$ versus $13.8 \%, \mathrm{p}=.001$ ).

Psychiatrists must be aware of these facts and carefully monitor and control patients with bipolar disorder for components of MetS and risk factors of cardiovascular diseases as part of the standard of care when treating these patients. Furthermore, specific programs should be implemented for patients with bipolar disorder aimed at reducing cigarette smoking, increasing exercise, and improving dietary habits.

Published: 22 April 2010

\section{References}

1. Birkenaes AB, Opjordsmoen S, Brunborg C, Engh JA, Jonsdottir $H$, Ringen PA, Simonsen C, Vaskinn A, Birkeland KI, Friis S, Sundet K, Andreassen OA: The level of cardiovascular risk factors in bipolar disorder equals that of schizophrenia: a comparative study. J Clin Psychiatry 2007, 68:917-23.

2. Correll $C U$, Frederickson AM, Kane JM, Manu P: Equally increased risk for metabolic syndrome in patients with bipolar disorder and schizophrenia treated with second-generation antipsychotics. Bipolar Disord 2008, 10:1-10.

3. Garcia-Portilla MP, Saiz PA, Benabarre A, Sierra P, Perez J, Rodriguez A, Livianos $L$, Torres $P$, Bobes $J$ : The prevalence of metabolic syndrome in patients with bipolar disorder. J Affect Disord 2008, 106:197-201.

4. Garcia-Portilla MP, Saiz PA, Bascaran MT, Martínez S, Benabarre A, Sierra P, Torres P, Montes JM, Bousoño M, Bobes J, on behalf of the General Health Status in Bipolar Disorder Collaborative Group: Cardiovascular risk in patients with bipolar disorder. J Affect Disord 2009, 115:302-308.

doi:10.1186/1744-859X-9-S1-S32

Cite this article as: Bobes: The general problem of increased somatic comorbidity in bipolar patients. Annals of General Psychiatry 2010 9(Suppl 1):S32. 